\title{
Urethral meatus stricture BOO stimulates bladder smooth muscle cell proliferation and pyroptosis via IL-1及 and the SGK1-NFAT2 signaling pathway
}

\author{
WANG KAI ${ }^{1,2^{*}}$, CHEN LIN $^{1,2^{*}}$, YANG JIN $^{1,2}$, HE PING-LIN $^{1}$, LIU XUN $^{1}$, AMEND BASTIAN $^{3}$, \\ STENZL ARNULF $^{3}, \mathrm{XING}_{\mathrm{SHA}-\mathrm{SHA}^{4}, \mathrm{LUO} \mathrm{XU}^{2} \text { and CUI SHU }}{ }^{5}$ \\ ${ }^{1}$ Department of Urology, Affiliated Hospital of Chengdu University, Chengdu, Sichuan 610041; \\ ${ }^{2}$ Department of Urology, Zunyi Medical University, Guiyang, Guizhou 563000, P.R. China; \\ ${ }^{3}$ Department of Urology, University of Tübingen, D-72070 Tübingen, Baden-Württemberg, Germany; \\ ${ }^{4}$ Central Laboratory, Affiliated Hospital of Chengdu University, Chengdu, Sichuan 610000; \\ ${ }^{5}$ Department of Urology, Affiliated Hospital of North Sichuan Medical College, \\ Nanchong, Sichuan 637000, P.R. China
}

Received August 5, 2019; Accepted March 25, 2020

DOI: $10.3892 / \mathrm{mmr} .2020 .11092$

\begin{abstract}
Bladder outlet obstruction (BOO), which is primarily caused by benign prostatic hyperplasia, is a common chronic disease. However, previous studies have most commonly investigated BOO using the acute obstruction model. In the present study, a chronic obstruction model was established to investigate the different pathological alterations in the bladder between acute and chronic obstruction. Compared with chronic obstruction, acute obstruction led to increased expression of proliferating cell nuclear antigen and interleukin-1 $\beta$, which are markers of proliferation and inflammation, respectively. Furthermore, increased fibrosis in the bladder at week 2 was observed. Low pressure promoted mice bladder smooth muscle cell (MBSMC) proliferation, and pressure overload inhibited cell proliferation and increased the proportion of dead MBSMCs. Further investigation using serum/glucocorticoid regulated kinase 1 (SGK1) small interfering RNAs indicated that low pressure may promote MBSMC proliferation by upregulating SGK1 and nuclear factor of activated T-cell expression levels. Therefore, the present study suggested that acute obstruction led to faster decompensation of bladder function and chronic bladder obstruction displayed an enhanced ability to progress to BOO.
\end{abstract}

Correspondence to: Dr Yang Jin, Department of Urology, Affiliated Hospital of Chengdu University, 82 Second Ring Road North 2nd, Chengdu, Sichuan 610041, P.R. China

E-mail: yangjindoctor@gmail.com

${ }^{*}$ Contributed equally

Key words: bladder outlet obstruction, bladder smooth muscle, fibrosis, proliferation, inflammation, pyroptosis, decompensation

\section{Introduction}

Bladder outlet obstruction (BOO), which is primarily caused by benign prostatic hyperplasia $(\mathrm{BPH})$, is a common disease in aging male individuals (1). BOO leads to urothelial inflammasome activity, bladder hypertrophy and fibrosis, and bladder smooth muscle cell (BSMC) proliferation (2,3). Stress stimulation, hypoxia and other conditions induce bladder remodeling during $\mathrm{BOO}$, which can also result in progressive tissue remodeling of the bladder $(4,5)$. Pathological alterations in BOO-induced bladder remodeling occur in three stages: hypertrophy, compensation and decompensation (6). Serum/glucocorticoid regulated kinase 1 (SGK1), a kinase under powerful genomic regulation and activated by phosphorylation via the phosphoinositol-3-phosphate signaling pathway, has been reported to regulate several enzymes and transcription factors. SGK1 contributes to the regulation of transport, hormone release, neuroexcitability, inflammation, cell proliferation and apoptosis $(7,8)$. Our previous study revealed that different cyclic hydrodynamic pressures display different effects on promoting the proliferation of human BSMCs (HBSMCs) cultured in scaffolds via the PI3K/SGK1 signaling pathway (9). The nuclear factor of activated T-cell (NFAT) family of transcription factors is composed of four calcium-responsive proteins (NFAT1-4). NFAT is important for regulating the survival, proliferation and function of multiple cell types, including mast cells, coronary endothelial cell and ventricular myocytes. NFAT has been reported to regulate heart valve development, skeletal and smooth muscle cell differentiation, and vascular development (10). In addition, numerous studies have demonstrated that NFAT2 plays a critical role in promoting cell proliferation (11-13). Therefore, it was hypothesized that SGK1 and NFAT2 may be associated with promoting mice BMSC (MBSMC) proliferation. During the decompensation phase of bladder remodeling, the wall contractility and emptying functions of the bladder deteriorate. During BOO, intravesical pressure increases, and if the stress on the cells is increased beyond the capacity of the compensatory 
responses, cells undergo pyroptosis (14). Therefore, we propose that acute obstruction could exacerbate cell pyroptosis, leading to rapid decompensation of bladder function.

Pressure stimulation of BMSCs during BOO is different compared with normal conditions. The majority of BOOs involve chronic and progressive pathological processes; however, previous findings have commonly used acute obstruction models that do not accurately mimic the natural course of BOO (15). A number of studies have reported that the mortality rate of BOO is usually $\geq 15 \%(16,17)$, even when a highly standardized method of obstruction, such as surgery, is applied to induce BOO (18). Cellular molecular mechanisms identified via traditional direct obstruction models may be inconsistent with the mechanisms underlying the progression of the clinical disease; therefore, developing an accurate model for investigating the pathogenesis of $\mathrm{BOO}$ is required.

In a previous study, a BOO model that successfully avoided trauma to the bladder was established (19). However, compared with human BPH, other models are potentially more acute and strict. In the present study, a method of gradually narrowing the outer urethra of mice to mimic the natural course of the BOO, based on previous research (9), was employed. This method involved inducing directly aggravated BOO (DBOO) and gradually aggravated BOO (GBOO) that displayed the $1 / 2$ urethral meatus stricture (UMS) at the same time, thus establishing the same degree of BOO. GBOO is a gradually developing model of BOO, but it typically models acute BOO. Accordingly, the present study aimed to investigate whether there was a difference in pathology between DBOO and GBOO.

\section{Materials and methods}

Animals. A total of 27 female BALB/c mice (age, 6-8 weeks; weight, 20-30 g) were purchased from the Dashuo Laboratory Animal Technology Co. Mice were housed at $24^{\circ} \mathrm{C}$ with $12-\mathrm{h}$ light/dark cycles, $35-40 \%$ humidity, and free access to food and water.

Mice were randomly divided into three groups ( $n=9$ per group): control, GBOO and DBOO. Animals in the BOO groups were subjected to isoflurane inhalation anesthesia prior to surgery. The method of BOO induction was performed as previously described (19). The GBOO group was pre-treated with this method before constructing the 1/2 UMS so the GBOO group displayed successfully established 1/3 UMS at 1 week and 1/4 UMS at 2 weeks prior to the establishment of $1 / 2$ UMS. Whereas, the DBOO group was not pre-treated before constructing the 1/2 UMS. The DBOO and GBOO groups displayed 1/2 UMS at the same time. The control group did not undergo any treatment. At 1, 2 and 4 weeks post-1/2 UMS construction, three mice from each group were euthanized. Bladder tissues were harvested and the bladder was cut horizontally into two pieces down the midline. Half of the bladder tissue was used for subsequent biochemical analyses, and the other half was fixed in $4 \%$ paraformaldehyde for one day at room temperature for subsequent histological analysis.

Western blotting. Bladder tissues were homogenized in RIPA lysis buffer (cat. no. CW2333S; CoWin Biosciences) containing a protease inhibitor. The protein concentration was detected by bicinchoninic acid protein assay kit (cat. no. CW0014; CoWin Biosciences). The homogenates were centrifuged at 15,000 x g for $10 \mathrm{~min}$ at $4^{\circ} \mathrm{C}$ and the supernatants were obtained. Proteins (50 $\mu \mathrm{g}$ per lane) were separated by SDS-PAGE on a $12 \%$ gel and transferred onto PVDF membranes. Non-specific binding was blocked with 5\% skimmed milk powder for $1 \mathrm{~h}$ at room temperature. Subsequently, the membranes were incubated overnight at $4^{\circ} \mathrm{C}$ with primary antibodies targeted against: NFAT2 (cat. no. ab175134; 1:1,000; Abcam), SGK1 (cat. no. ab59337; 1:1,000; Abcam), proliferating cell nuclear antigen (PCNA; cat. no. D3H8PXP; 1:1,000; Cell Signaling Technology, Inc.), interleukin (IL)-1 $\beta$ (cat. no. 3A6; 1:1,000; Cell Signaling Technology, Inc.) and $\beta$-actin (cat. no. ab8227; 1:1,000; Abcam). Following primary incubation, the membranes were washed three times for $10 \mathrm{~min}$ in PBS with $0.1 \%$ Tween-20 and subsequently incubated with horseradish peroxidase conjugated-secondary antibodies (cat. nos. 7074P2 and 7076P2; 1:5,000; Cell Signaling Technology, Inc.) for $1 \mathrm{~h}$ at room temperature with slow shaking. The membranes were washed again three times for 10 min in PBS with $0.1 \%$ Tween-20. Protein bands were visualized by a ChemiDoc XRS+ system (Bio-Rad Laboratories, Inc.) using an enhanced chemiluminescence kit (Thermo Fisher Scientific, Inc.). Protein expression was quantified using the Image Lab software 5.2.1 (Bio-Rad Laboratories, Inc.). $\beta$-actin was used as the loading control.

Histological analysis. Bladder tissue was fixed in $4 \%$ paraformaldehyde for $24 \mathrm{~h}$ at $4^{\circ} \mathrm{C}$ and subsequently embedded in paraffin. The paraffin-embedded tissue samples were cut into 5- $\mu \mathrm{m}$ sections. Histopathology was detected by Masson's trichrome staining for $15 \mathrm{~min}$ at room temperature. Samples were observed and imaged using an ortho-fluorescence microscope (Nikon Corporation) at magnification, x100 or x200. The detrusor muscle and collagen content were quantified using ImagePro Plus 6.0 software (Media Cybernetics, Inc.).

Isolation and culture of BMSCs. Bladder tissue was cut into pieces and digested in PBS containing $0.4 \mathrm{mg} / \mathrm{ml}$ type II collagenase (cat. no. 17101015; Gibco; Thermo Fisher Scientific, Inc.) at $37^{\circ} \mathrm{C}$ for $60 \mathrm{~min}$ with $5 \% \mathrm{CO}_{2}$ and $95 \% \mathrm{O}_{2}$. Subsequently, the suspensions were centrifuged at $1,300 \mathrm{x} \mathrm{g}$ for $5 \mathrm{~min}$ at $4^{\circ} \mathrm{C}$ and the supernatants were discarded. MBSMCs were cultured in DMEM (cat.no. 12430054; Gibco; Thermo Fisher Scientific, Inc.) supplemented with $10 \%$ fetal bovine serum (cat. no. 16000044; Gibco; Thermo Fisher Scientific, Inc.), $100 \mathrm{U} / \mathrm{ml}$ penicillin and $100 \mu \mathrm{g} / \mathrm{ml}$ streptomycin at $37^{\circ} \mathrm{C}$ with $5 \% \mathrm{CO}_{2}$ and $95 \% \mathrm{O}_{2}$.

Cyclic hydrodynamic pressure. MBSMCs were cultured in scaffolds and subsequently serum-starved for $12 \mathrm{~h}$ at $37^{\circ} \mathrm{C}$. A total of $\sim 1 \times 10^{5}$ cells were seeded onto a silicone membrane and subjected to cyclic hydrodynamic pressure to simulate the bladder cycle for up to $24 \mathrm{~h}$ ( $2 \mathrm{~h}$ per cycle) at $37^{\circ} \mathrm{C}$ as follows: $1.75 \mathrm{~h}$ increasing from 0 to $10 \mathrm{cmH}_{2} \mathrm{O}$; rapid increase up to 200 or $400 \mathrm{cmH}_{2} \mathrm{O}$; 200 or $400 \mathrm{cmH}_{2} \mathrm{O}$ maintained for $0.25 \mathrm{~h}$; and returned to $0 \mathrm{cmH}_{2} \mathrm{O}$. No pressure was applied to the control group.

Cell transfection. An siRNA ( $1 \mu \mathrm{l}$; cat. no. 18358; Shanghai GenePharma Co., Ltd.) targeting SGK1 was transfected using Lipofectamine $^{\mathrm{TM}} 2000$ reagent (cat. no. 11668019; Thermo Fisher Scientific, Inc.), Scrambled siRNAs ( $1 \mu 1$; cat. no. 0806; Shanghai GenePharma Co., Ltd.), according to the manufacturer's protocol. Mice BSMCs at $80 \%$ density were transfected 


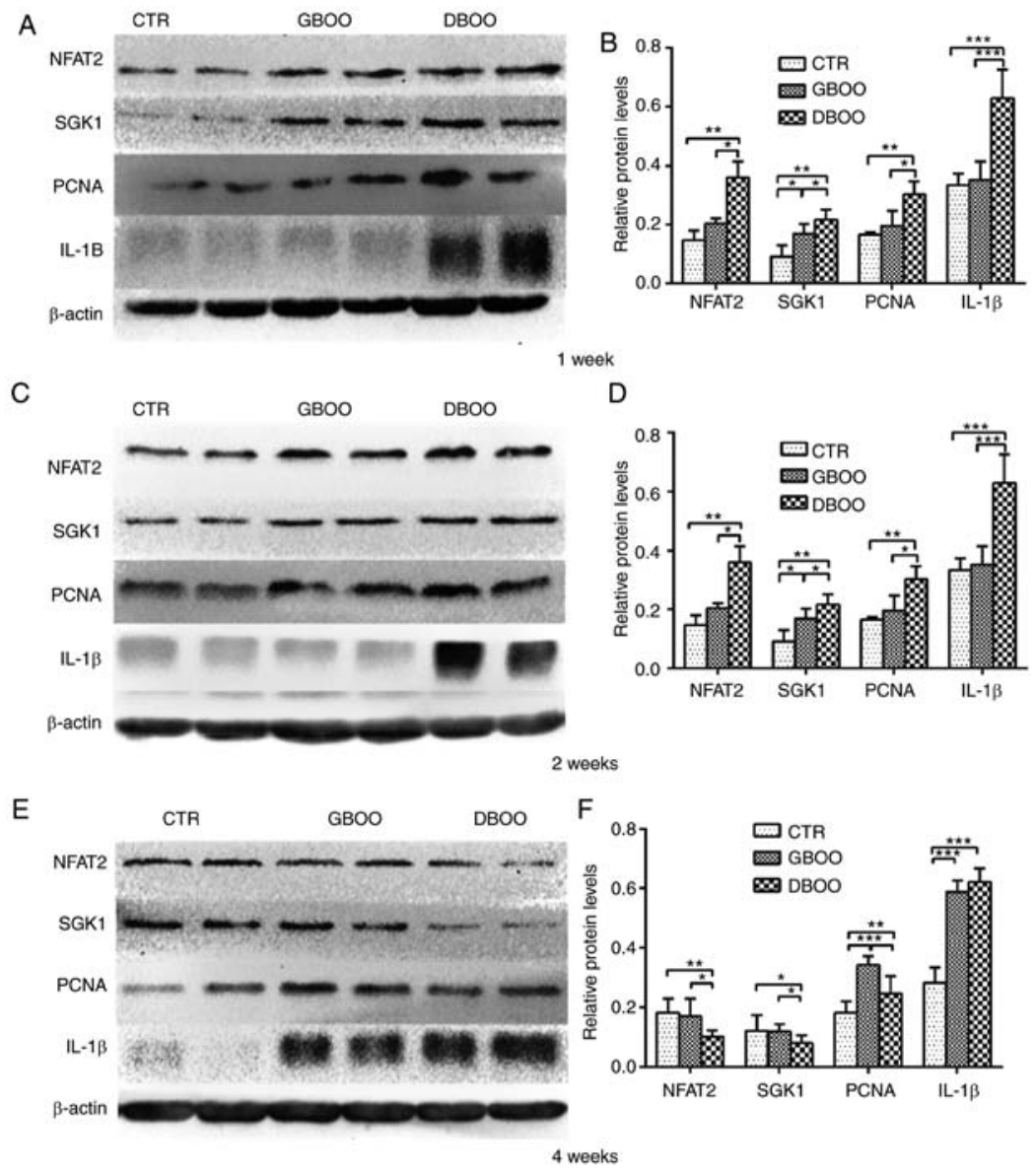

Figure 1. Protein expression in the bladder at week 1,2 and 4 was determined by western blot analysis. Protein expression in the bladder at week 1 was (A) determined by western blotting and (B) quantified. Protein expression in the bladder at week 2 was (C) determined by western blotting and (D) quantified. Protein expression in the bladder at week 4 was (E) determined by western blotting and (F) quantified. ${ }^{*} \mathrm{P}<0.05,{ }^{* *} \mathrm{P}<0.01$ and ${ }^{* * *} \mathrm{P}<0.005$, as indicated. CTR, control; BOO, bladder outlet obstruction; GBOO, gradually aggravated BOO; DBOO, directly aggravated BOO; NFAT2, nuclear factor of activated T cells 2; SGK1, serum/glucocorticoid regulated kinase 1; PCNA, proliferating cell nuclear antigen; IL-1 $\beta$, interleukin-1 $\beta$.

twice at an interval of $24 \mathrm{~h}$ with SGK1 siRNAs. Subsequent experiments was performed $72 \mathrm{~h}$ after transfection. The siRNA sequences used were: SGK1 (A), sense: 5'-GUCCUUCUCAG CAAAUCAAUU-3' and antisense: 5'-UUGAUUUGCUGAGA AGGACUU-3'; SGK1 (B), sense: 5'-CCUGAGCUUAUGAA UGCCAACCCUU-3' and antisense: 5'-AAGGGUUGGCAUU CAUAAGCUCAGG-3'; scramble siRNA, sense: 5'-UUCUCC GAACGUGUCACGUTT-3' and antisense: 5'-ACGUGACACG UUCGGAGAATT-3'.

Cell cycle analysis via flow cytometry. MBSMCs were seeded into scaffolds $\left(5 \times 10^{6}\right.$ cells/scaffolds $)$ for $24 \mathrm{~h}$ at room temperature, collected and fixed in $70 \%$ ethanol overnight at $4^{\circ} \mathrm{C}$. After centrifugation at $1,300 \mathrm{x} \mathrm{g}$ for $5 \mathrm{~min}$ at $4^{\circ} \mathrm{C}$, the pellet was treated with PBS containing $50 \mathrm{mg} / \mathrm{ml}$ RNase A (cat. no. EN0531; Thermo Fisher Scientific, Inc.) and incubated at $37^{\circ} \mathrm{C}$ for $1 \mathrm{~h}$. The pellet was washed with ice-cold PBS and resuspended in $1 \mathrm{ml}$ propidium iodide $4^{\circ} \mathrm{C}$ for $1 \mathrm{~h}$ in the dark. Cell cycle distribution was analyzed using an EPICS ELITE ESP flow cytometer (Beckman Coulter, Inc.) and MultiCycle for Windows 32-bit (Phoenix Flow Systems, Inc.). The number of cells used for detection was $\geq 10,000$ per sample. The cell proliferation index was calculated as follows: proliferation index $(\%)=\left(\mathrm{S}+\mathrm{G}_{2} / \mathrm{M}\right) /\left(\mathrm{G}_{0} / \mathrm{G}_{1}+\mathrm{S}+\mathrm{G}_{2} / \mathrm{M}\right) \times 100 \%$.
Statistical analysis. Data are presented as the mean \pm SEM. Comparisons among multiple groups were performed using one-way ANOVA followed by the Least Significant Difference post hoc test. Statistical analyses were performed using SPSS software version 22 (IBM Corp.). $\mathrm{P}<0.05$ was considered to indicate a statistically significant difference.

\section{Results}

$D B O O$ causes a stronger inflammatory and proliferative response compared with $\mathrm{GBOO}$ during the early stage of $\mathrm{BOO}$. NFAT2 and PCNA protein expression levels were significantly increased in the DBOO groups compared with the control group at week $1(\mathrm{P}<0.05)$, but expression levels were not significantly increased in the GBOO group compared with the control group $(\mathrm{P}=0.194$ and $\mathrm{P}=0.136$, respectively). Whereas, protein expression of SGK1 was significantly increased in both the DBOO and GBOO group compared with the control $(\mathrm{P}<0.05)$. Furthermore, the expression levels of NFAT2, SGK1 and PCNA were significantly higher in the DBOO group compared with the GBOO group $(\mathrm{P}<0.05)$. No significant differences were observed for IL-1 $\beta$ expression levels between the GBOO and control groups $(\mathrm{P}=0.954)$. However, IL-1 $\beta$ expression levels were significantly higher in the DBOO group compared with the control and GBOO groups $(\mathrm{P}<0.05)$ (Fig. 1A and $\mathrm{B})$. 

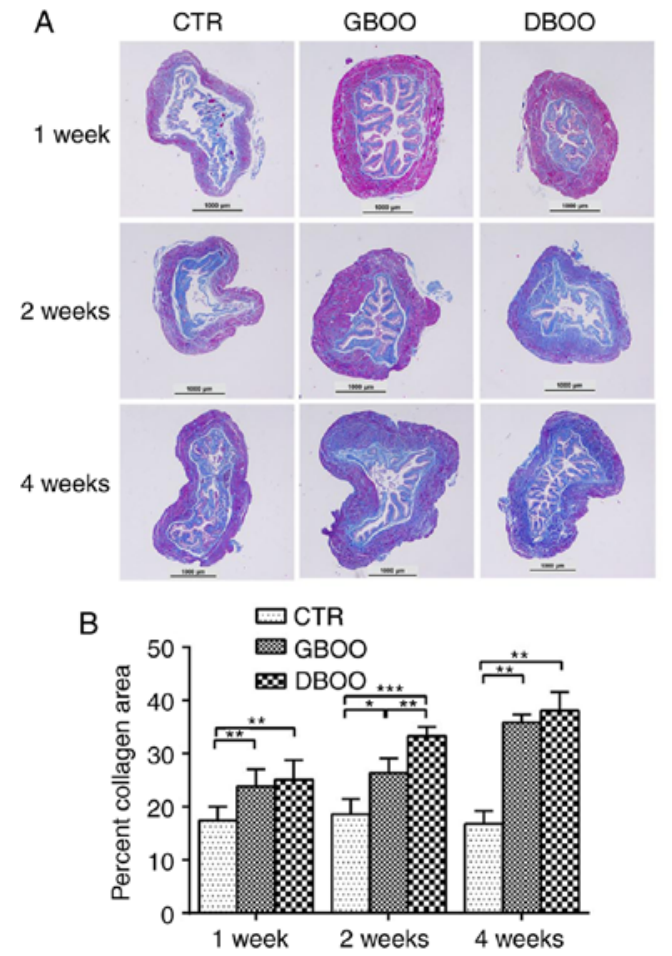

Figure 2. Histologic analysis of bladder morphology during BOO. (A) Masson's trichrome staining was used to assess collagen (blue) and smooth muscle (red) with (B) subsequent quantification. ${ }^{*} \mathrm{P}<0.05,{ }^{* *} \mathrm{P}<0.01$ and ${ }^{* * * *} \mathrm{P}<0.005$, as indicated. BOO, bladder outlet obstruction; CTR, control; $\mathrm{GBOO}$, gradually aggravated $\mathrm{BOO}$; $\mathrm{DBOO}$, directly aggravated $\mathrm{BOO}$.

The expression levels of NFAT2, SGK1 and PCNA in the DBOO groups were significantly higher compared with the control group at week $2(\mathrm{P}<0.05)$, but expression of NFAT2 and PCNA was not significantly increased in the GBOO group compared with the control $(\mathrm{P}=0.095$ and $\mathrm{P}=0.085$, respectively). Whereas, SGK1 expression did significantly increase in the GBO group compared with the control $(\mathrm{P}<0.05)$. Compared with the GBOO group, the DBOO group showed increased NFAT2, SGK1 and PCNA expression levels $(\mathrm{P}<0.05)$. The level of IL-1 $\beta$ expression in the DBOO group was significantly increased compared with the control and GBOO groups $(\mathrm{P}<0.05)$; however, IL-1 $\beta$ expression levels were not significantly different between the control and GBOO groups ( $\mathrm{P}=0.180$ ) (Fig. $1 \mathrm{C}$ and $\mathrm{D})$.

At week 4, the control and GBOO groups showed similar NFAT2 $(\mathrm{P}=0.323)$ and SGK1 $(\mathrm{P}=0.787)$ expression levels. NFAT2 and SGK1 expression levels were downregulated in the DBOO group compared with the control and GBOO groups $(\mathrm{P}<0.05)$. PCNA expression in the GBOO and DBOO groups was significantly higher compared with the control group $(\mathrm{P}<0.05)$, and PCNA expression was significantly decreased in the DBOO group compared with the GBOO group $(\mathrm{P}<0.05)$. The level of IL-1 $\beta$ expression in the GBOO and DBOO groups was significantly increased compared with the control group $(\mathrm{P}<0.05)$. In addition, IL-1 $\beta$ expression levels were not significantly different between the DBOO and GBOO groups $(\mathrm{P}=0.076)$ (Fig. 1E and F).

DBOO leads to increased collagen deposition compared with GBOO during the early stage of BOO. At week 1, the area percentage of collagen in the bladder tissues was higher in the GBOO $(23.83 \pm 3.20 \%)$ and DBOO groups $(25.10 \pm 3.65 \%)$ compared with the control group $(17.39 \pm 2.62 \%$; $\mathrm{P}<0.05)$. However, there was no significant difference between the GBOO and DBOO groups $(\mathrm{P}=0.413)$. At week 2 , the DBOO group $(33.31 \pm 1.71 \%)$ showed a significantly higher area percentage of collagen compared with the GBOO $(26.33 \pm 2.81 \%)$ and control $(18.66 \pm 2.77 \%)$ groups $(\mathrm{P}<0.05)$. At week 4 , the area percentage of collagen in the bladder was increased in the GBOO $(35.80 \pm 1.50 \%)$ and DBOO groups $(38.12 \pm 3.48 \%)$ compared with the control group $(16.79 \pm 2.50 \%$; $\mathrm{P}<0.05)$. The area percentage of collagen between the GBOO and DBOO groups was not significantly different at week 4 $(\mathrm{P}=0.735)$ (Fig. 2A and $\mathrm{B})$.

Low cyclic hydrodynamic pressure promotes MBSMC proliferation and high cyclic hydrodynamic pressure promotes cell death. The results indicated that $200 \mathrm{cmH}_{2} \mathrm{O}$ cyclic pressure significantly promoted cell proliferation compared with the control group and $400 \mathrm{cmH}_{2} \mathrm{O}$ group. The proliferation index was significantly increased from $18.59 \pm 2.38 \%$ in the control group to $31.79 \pm 1.58$ and $26.64 \pm 3.99 \%$ in the 200 and $400 \mathrm{cmH}_{2} \mathrm{O}$ pressure groups, respectively $(\mathrm{P}<0.05)$ (Fig. 3A and B). The proportion of dead cells was significantly increased in the $200 \mathrm{cmH}_{2} \mathrm{O}(1.32 \pm 0.11 \%)$ and $400 \mathrm{cmH}_{2} \mathrm{O}$ $(4.73 \pm 0.37 \%)$ pressure groups compared with the control group $(0.0333 \pm 0.01 \%)$ (Fig. $3 \mathrm{~A}$ and C). The results suggested that excessive stress promoted cell death in MBSMCs.

NFAT2, SGK1 and PCNA expression is significantly increased under the stimulation of $200 \mathrm{cmH}_{2} \mathrm{O}$ pressure, and SGKI knockdown induces a decrease in NFAT2 expression. The expression level of NFAT2 was significantly decreased in the SGK1 siRNA group compared with the scrambled siRNA group (Fig. $4 \mathrm{C}$ and D). The results suggested that 200 and $400 \mathrm{cmH}_{2} \mathrm{O}$ pressure increased NFAT2, SGK1 and PCNA expression compared with the control group $(\mathrm{P}<0.05)$ (Fig. 4A and B). In addition, a significant increase in NFAT2, SGK1 and PCNA expression was observed in the $200 \mathrm{cmH}_{2} \mathrm{O}$ group compared with the $400 \mathrm{cmH}_{2} \mathrm{O}$ group. IL-1 $\beta$ protein expression levels were not significantly altered between the control, 200 and $400 \mathrm{cmH}_{2} \mathrm{O}$ groups (Fig. 4A and B).

\section{Discussion}

Previous studies have reported that pressure can promote proliferation, inflammation and extracellular matrix (ECM) remodeling in BSMCs (20-22). Obstructed bladder dysfunction secondary to BPH is a slow and progressive disease (6). Ideally, an accurate model of BPH-induced BOO would develop as gradually as possible (15). In the present study, a significant difference in the pathology between the DBOO group and the GBOO group was observed, which provided evidence that GBOO may serve as a more appropriate model for studying BOO.

BOO significantly alters the structure and function of the bladder $(23,24)$, due to BMSC stimulation by increased pressure $(25,26)$. A previous study supported the hypothesis that the natural progression of $\mathrm{BOO}$ is characterized by three morphofunctional stages: an initial hypertrophy phase, a 
A

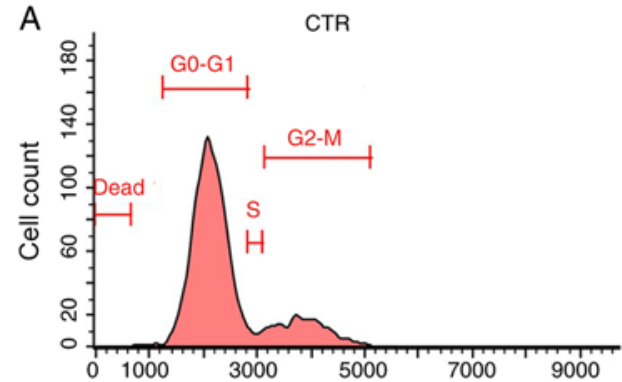

B

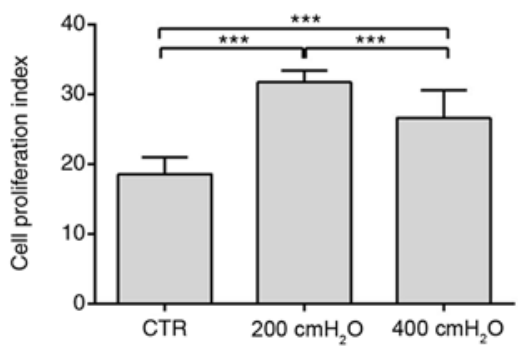

$200 \mathrm{cmH}_{2} \mathrm{O}$

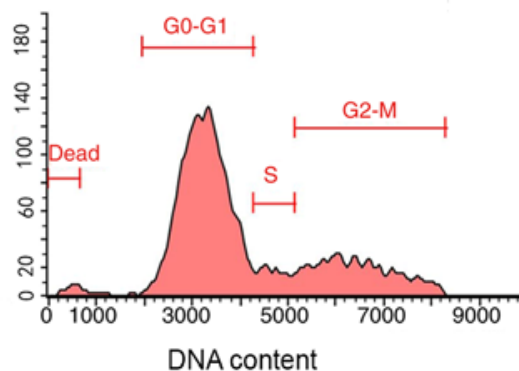

$400 \mathrm{cmH}_{2} \mathrm{O}$

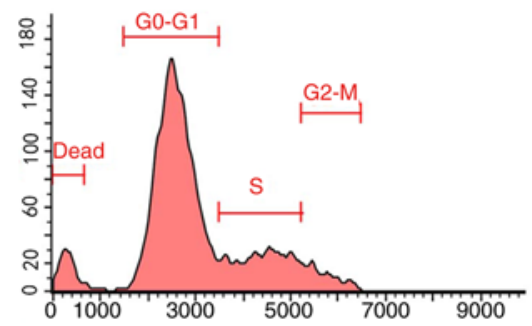

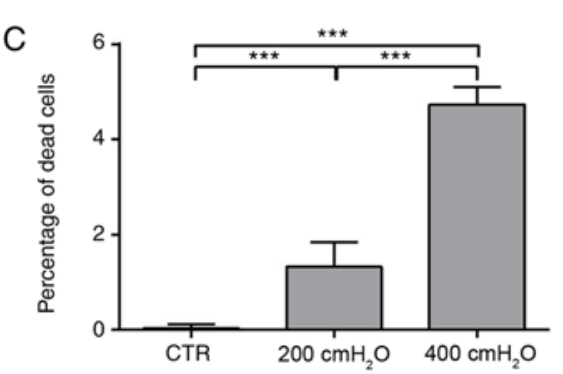

Figure 3. Mouse bladder smooth muscle cells were exposed to 24-h cyclic hydrodynamic pressure. (A) Representative flow cytometry profiles of the cell cycle distribution. (B) Quantification of the cell proliferation index. (C) Quantification of apoptotic cells. ${ }^{* * *} \mathrm{P}<0.005$, as indicated. CTR, control.
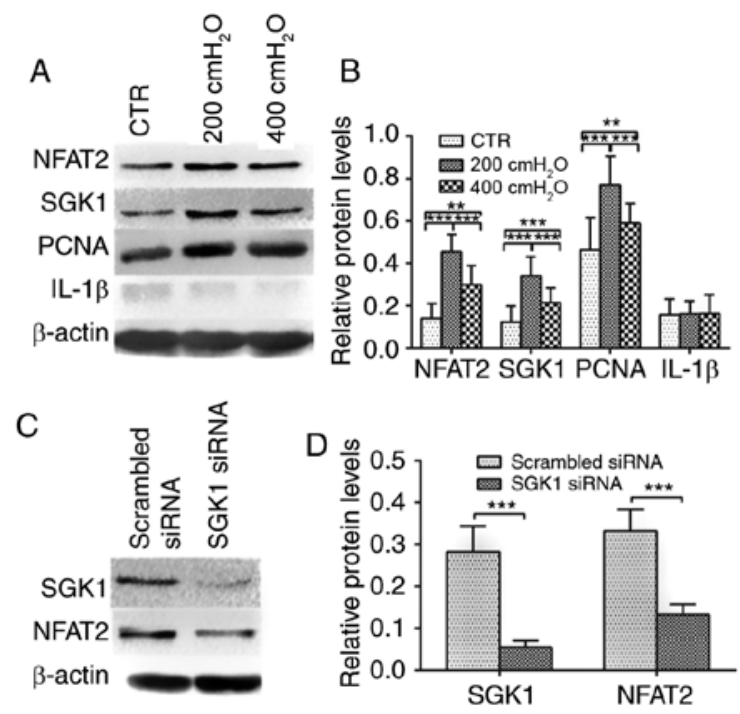

Figure 4. Protein expression levels in mouse bladder smooth muscle cells following exposure to cyclic hydrodynamic pressure. NFAT2 protein levels were significantly decreased in the SGK1 siRNA group compared with the scrambled siRNA group. Protein expression levels of NFAT2, SGK1, PCNA and IL-1 $\beta$ were (A) determined by western blotting and (B) quantified. Protein expression levels of SGK1 and NFAT2 following SGK1 siRNA transfection were (C) determined by western blotting and (D) quantified. ${ }^{* *} \mathrm{P}<0.01$ and ${ }^{* * *} \mathrm{P}<0.005$, as indicated. NFAT2, nuclear factor of activated $\mathrm{T}$ cells 2 ; SGK1, serum/glucocorticoid regulated kinase 1; siRNA, small interfering RNA; PCNA, proliferating cell nuclear antigen; IL-1 $\beta$, interleukin-1 $\beta$; CTR, control.

subsequent compensatory phase and a late decompensation phase (20). A number of studies have reported that stressful stimuli promote the proliferation of BSMCs via multiple pressure-dependent pathways (9,27-29). In our previous study, pressure promoted HBSMC proliferation, which may be caused by increased stress during the compensation stage of BOO (3). During BOO, BSMCs are stimulated by higher than normal hydrostatic pressure (30). In our previous study, cyclic hydrodynamic pressure stimulated the proliferation of HBSMCs via SGK1 (9). Previous findings have also demonstrated that NFAT2 enhances the expression of cyclins, particularly cyclin D1, in vascular smooth muscle cells to mediate their proliferation $(31,32)$. It was hypothesized that SGK1 promoted the proliferation of BSMCs under pressure, which may be achieved by regulating NFAT2. Therefore, the expression levels of SGK1 and NFAT2 in mice were investigated. In the present study, SGK1 and NFAT2 expression levels were upregulated during the early stages of BOO, and SGK1-siRNA treatment reduced NFAT2 expression. The results indicated a relationship between SGK1 and NFAT2, and suggested that pressure promoted MBSMC proliferation, potentially by upregulating the expression of SGK1 and NFAT2. However, the present study did not identify a direct relationship between the two factors. To further investigate the interaction between SGK1 and NFAT2, coimmunoprecipitation was performed; however, the experimental results were unsatisfactory (data not shown). A limitation of the present study was that the interactions within the SGK1-NFAT2 signaling pathway were not identified.

The expression of SGK1 and NFAT2 was upregulated in the DBOO group compared with the GBOO group at week 1 and 2 post-obstruction. However, the expression of SGK1 and NFAT2 in the DBOO group was lower compared with the GBOO group and the control group at week 4 post-obstruction. PCNA is an indicator of cell proliferation $(33,34)$, and the PCNA expression pattern was consistent with that of SGK1 and NFAT2 at week 1 and 2 in the present study. The results indicated that the bladder displayed a stronger proliferative response to acute obstruction compared with chronic obstruction. In particular, $200 \mathrm{cmH}_{2} \mathrm{O}$ cyclic pressure significantly increased MBSMC proliferation; however, $400 \mathrm{cmH}_{2} \mathrm{O}$ cyclic pressure stimulation resulted in a significant decrease in cell proliferation compared with $200 \mathrm{cmH}_{2} \mathrm{O}$ 
cyclic pressure stimulation. The results suggested that pressure overload decreased MBSMC proliferation. The level of BMSC proliferation increases during the compensation phase but decreases during the decompensation phase $(35,36)$. The expression of SGK1 and NFAT2 in the DBOO group was lower compared with the GBOO and control groups at week 4 post-obstruction, and the expression of PCNA in the DBOO group was decreased compared with the GBOO group. As PCNA is a marker of proliferation, this suggested that cell proliferation in the DBOO group was decreased compared with the GBOO group. The results indicated that mice in the DBOO group showed bladder decompensation at week 4 post-obstruction. Therefore, the present study suggested that chronic obstruction resulted in a longer compensatory period in the bladder, whereas acute obstruction led to faster decompensation of bladder function.

Pressure promotes BMSC proliferation and inflammation $(21,37)$. Recent studies have demonstrated that inflammatory cytokines mediate the maturation of IL-1 $\beta$ and lead to pyroptosis $(38,39)$. In the present study, pressure stimulation significantly increased cell death, and the proportion of dead cells was increased in the 200 and $400 \mathrm{cmH}_{2} \mathrm{O}$ pressure groups compared with the control group. IL-1 $\beta$ expression was assessed at different time points following $\mathrm{BOO}$ induction. The GBOO and DBOO groups showed upregulated IL- $1 \beta$ expression compared with the control group at the three different time points. The DBOO group displayed a stronger inflammatory response at week 1 and 2 post-obstruction compared with the GBOO group; however, the enhanced response was not observed at week 4 post-obstruction. The bladder cannot accommodate a sudden increase in intravesical pressure during acute obstruction (40), which results in the aggravation of inflammation. As indicated by the expression levels of the aforementioned biomarkers, the DBOO group displayed decreased proliferation and increased inflammation at an earlier time point compared with the GBOO group, suggesting that the DBOO group may have experienced bladder function decompensation at an earlier time point. Therefore, it was hypothesized that a pressure overload-induced decrease in proliferation and increase in pyroptosis of BSMCs could play an important role during the bladder decompensation phase of BOO. The results suggested that acute obstruction may cause rapid decompensation of bladder function by aggravating inflammation-mediated pyroptosis and decreasing the proliferation of BSMCs.

Bladder remodeling induced by BOO leads to impaired storage and emptying of the bladder, which is characterized by increased collagen accumulation $(41,42)$. Increased collagen deposition in the ECM is a key reason for decreased compliance $(43,44)$. Previous studies have reported that pressure promotes an increase in ECM production around BSMCs $(45,46)$. Although the DBOO group was obstructed for a shorter period of time compared with the GBOO group and both groups were subjected to the same degree of obstruction, collagen deposition occurred earlier and more significantly in the DBOO group. In addition, the collagen deposition in the DBOO group was more pronounced compared with the GBOO group at week 2 post-obstruction. The bladders of mice in the GBOO group were obstructed prior to constructing 1/2 UMS; therefore, the bladder could adapt to the obstruction, suggesting that the chronically obstructed bladder indicated an increased ability to adapt to obstruction and a longer compensatory period. High levels of collagen deposition induce a decrease in bladder compliance, leading to bladder decompensation; therefore, acute obstruction may cause rapid decompensation of bladder function $(47,48)$.

In conclusion, the chronically obstructed bladder displayed a greater ability to adapt to obstruction and a longer compensatory period. The results suggested that the bladder did not adapt to a sudden increase in intravesical pressure caused by acute obstruction, which resulted in increased proliferation, inflammation and fibrosis. The present study indicated that acute obstruction may lead to faster decompensation of bladder function.

\section{Acknowledgements}

Not applicable.

\section{Funding}

The present study was supported by the National Natural Science Foundation of China (grant no. 81500577), the Research Project from the Department of Science and Technology of Sichuan Province (grant nos. 2017JY0097 and 19YYJC1427) and the Research Projects of Chengdu Science and Technology (grant no. 2015-HM01-00580-SF).

\section{Availability of data and materials}

The datasets used and/or analyzed during the current study are available from the corresponding author on reasonable request.

\section{Authors' contributions}

WK, HPL and LX conceived and designed the study protocol, collected data and performed data analysis. CL, YJ, AB, SA, XSS, LX and CS designed the study. YJ was involved in designing the study, data analysis and writing/editing the manuscript. All authors read and approved the final manuscript.

\section{Ethics approval and consent to participate}

The present study was approved by the Animal Ethics Committee of the Affiliated Hospital of Chengdu University.

\section{Patient consent for publication}

Not applicable.

\section{Competing interests}

The authors declare that they have no competing interests.

\section{References}

1. Singla S, Garg R, Singla A, Sharma S, Singh J and Sethi P: Experience with uroflowmetry in evaluation of lower urinary tract symptoms in patients with benign prostatic hyperplasia. J Clin Diagn Res 8: NC01-NC03, 2014. 
2. Hughes FM Jr, Hill HM, Wood CM, Edmondson AT, Dumas A Foo WC, Oelsen JM, Rac G and Purves JT: The NLRP3 Inflammasome Mediates Inflammation Produced by Bladder Outlet Obstruction. J Urol 195: 1598-1605, 2016.

3. Niederhoff RA, Manson SR, Tawfik A and Austin PF: The physiological significance of $\mathrm{p} 27$ (KIP1) expression in detrusor function. J Urol 184 (Suppl): 1686-1691, 2010.

4. Kanno Y,Mitsui T,Kitta T,Moriya K, Tsukiyama T,Hatakeyama S and Nonomura K: The inflammatory cytokine IL-1 $\beta$ is involved in bladder remodeling after bladder outlet obstruction in mice. Neurourol Urodyn 35: 377-381, 2016.

5. Liu Q, Luo D, Yang T, Liao B, Li H and Wang KJ: Protective Effects of Antimuscarinics on the Bladder Remodeling After Bladder Outlet Obstruction. Cell Physiol Biochem 44: 907-919, 2017.

6. Levin R, Chichester P, Levin S and Buttyan R: Role of angiogenesis in bladder response to partial outlet obstruction. Scand J Urol Nephrol Suppl 215: 37-47, 2004.

7. Lou Y, Hu M, Mao L, Zheng Y and Jin F: Involvement of serum glucocorticoid-regulated kinase 1 in reproductive success. FASEB J 31: 447-456, 2017.

8. Lang F, Stournaras C, Zacharopoulou N, Voelkl J and Alesutan I: Serum- and glucocorticoid-inducible kinase 1 and the response to cell stress. Cell Stress 3: 1-8, 2018

9. Chen L, Wei TQ, Wang Y, Zhang J, Li H and Wang KJ: Simulated bladder pressure stimulates human bladder smooth muscle cell proliferation via the PI3K/SGK1 signaling pathway. J Urol 188 : 661-667, 2012

10. Li R, Zhang L, Shi W, Zhang B, Liang X, Liu S and Wang W: NFAT2 mediates high glucose-induced glomerular podocyte apoptosis through increased Bax expression. Exp Cell Res 319: 992-1000, 2013.

11. Liu X, Pan CG and Luo ZQ: High expression of NFAT2 contributes to carboplatin resistance in lung cancer. Exp Mol Pathol 110: 104290, 2019

12. Vaeth M, Bäuerlein CA, Pusch T, Findeis J, Chopra M, Mottok A, Rosenwald A, Beilhack A and Berberich-Siebelt F: Selective NFAT targeting in T cells ameliorates GvHD while maintaining antitumor activity. Proc Natl Acad Sci USA 112: $1125-1130,2015$.

13. Ram BM, Dolpady J, Kulkarni R, Usha R, Bhoria U, Poli UR, Islam M, Trehanpati N and Ramakrishna G: Human papillomavirus (HPV) oncoprotein E6 facilitates Calcineurin-Nuclear factor for activated T cells 2 (NFAT2) signaling to promote cellular proliferation in cervical cell carcinoma. Exp Cell Res 362: 132-141, 2018.

14. Lee MK, Lee SH, Hur N, Kim S, Kim S and Choi B: Correlation between intravesical pressure and prostatic obstruction grade using computational fluid dynamics in benign prostatic hyperplasia. Proc Inst Mech Eng H 225: 920-928, 2011.

15. Kitta T, Kanno Y, Chiba H, Higuchi M, Ouchi M, Togo M, Moriya K and Shinohara N: Benefits and limitations of animal models in partial bladder outlet obstruction for translational research. Int J Urol 25: 36-44, 2018.

16. Schröder A, Tajimi M, Matsumoto H, Schröder C, Brands M and Andersson KE: Protective effect of an oral endothelin converting enzyme inhibitor on rat detrusor function after outlet obstruction. J Urol 172: 1171-1174, 2004.

17. Kang YJ, Jin LH, Park CS, Shin HY, Yoon SM and Lee T: Early sequential changes in bladder function after partial bladder outlet obstruction in awake sprague-dawley rats: Focus on the decompensated bladder. Korean J Urol 52: 835-841, 2011.

18. de Jongh R, van Koeveringe GA, van Kerrebroeck PE, Markerink-van Ittersum M, de Vente J and Gillespie JI: Damage to the bladder neck alters autonomous activity and its sensitivity to cholinergic agonists. BJU Int 100: 919-929, 2007.

19. Chen L, Yang Y, Yang J, He P, Amend B, Stenzl A, Hu J, Zhang Y and Wang Z: Suture causing urethral meatus stricture: A novel animal model of partial bladder outlet obstruction. Neurourol Urodyn 37: 2088-2096, 2018

20. Fusco F, Creta M, De Nunzio C, Iacovelli V, Mangiapia F, Li Marzi V and Finazzi Agrò E: Progressive bladder remodeling due to bladder outlet obstruction: A systematic review of morphological and molecular evidences in humans. BMC Urol 18: 15, 2018.

21. Liang Z, Xin W, Qiang L, Xiang C, Bang-Hua L, Jin Y, De-Yi L, Hong L and Kun-Jie W: Hydrostatic pressure and muscarinic receptors are involved in the release of inflammatory cytokines in human bladder smooth muscle cells. Neurourol Urodyn 36 : $1261-1269,2017$
22. Sun Y, Luo D, Zhu Y, and Wang K: MicroRNA 4323 induces human bladder smooth muscle cell proliferationunder cyclic hydrodynamic pressure by activation of erk $1 / 2$ signaling pathway. Exp. Biol. Med. (Maywood), 242: 169-176, 2017.

23. Kitta T, Kakizaki H, Tanaka H, Sano H, Furuno T, Mitsui T, Moriya K and Nonomura K: An alpha-amino-3-hydroxy-5-me thyl-4-isoxazolepropionate glutamate-receptor antagonist can inhibit premicturition contractions in rats with bladder outlet obstruction. BJU Int 100: 181-186, 2007.

24. Metcalfe PD, Wang J, Jiao H, Huang Y, Hori K, Moore RB and Tredget EE: Bladder outlet obstruction: Progression from inflammation to fibrosis. BJU Int 106: 1686-1694, 2010.

25. McGuire EJ, Woodside JR, Borden TA and Weiss RM: Prognostic value of urodynamic testing in myelodysplastic patients. J Urol 126: 205-209, 1981

26. Engel JD, Jacobs D, Konsur B, Megaridis CM and Bushman W: Urodynamic evaluation of the human bladder response to an increase in outlet resistance. Neurourol Urodyn 21: 524-528, 2002.

27. Wei TQ, Luo DY, Chen L, Wu T and Wang KJ: Cyclic hydrodynamic pressure induced proliferation of bladder smooth muscle cells via integrin alpha5 and FAK. Physiol Res 63: 127-134, 2014

28. Sun Y, Luo DY, Zhu YC, Zhou L, Yang TX, Tang C, Shen H and Wang KJ: MiR 3180-5p promotes proliferation in human bladder smooth muscle cell by targeting PODN under hydrodynamic pressure. Sci Rep 6: 33042, 2016.

29. Sun Y, Luo D, Zhu Y and Wang K: MicroRNA 4323 induces human bladder smooth muscle cell proliferation under cyclic hydrodynamic pressure by activation of erk $1 / 2$ signaling pathway. Exp Biol Med (Maywood) 242: 169-176, 2017.

30. Reddy SVK and Shaik AB: Non-invasive evaluation of bladder outlet obstruction in benign prostatic hyperplasia: A clinical correlation study. Arab J Urol 17: 259-264, 2019.

31. Karpurapu M, Wang D, Van Quyen D, Kim TK, Kundumani-Sridharan V,Pulusani S and Rao GN: Cyclin D1 is a bona fide target gene of NFATc1 and is sufficient in the mediation of injury-induced vascular wall remodeling. J Biol Chem 285: $3510-3523,2010$

32. Liu J, Jin P, Lin X, Zhou Q, Wang F, Liu S and Xi S: Arsenite increases Cyclin D1 expression through coordinated regulation of the $\mathrm{Ca}^{2+} / \mathrm{NFAT} 2$ and NF- $\kappa \mathrm{B}$ pathways via ERK/MAPK in a human uroepithelial cell line. Metallomics 10: 486-495, 2018.

33. Zölzer F, Basu O, Devi PU, Mohanty SP and Streffer C: Chromatin-bound PCNA as S-phase marker in mononuclear blood cells of patients with acute lymphoblastic leukaemia or multiple myeloma. Cell Prolif 43: 579-583, 2010.

34. Sirotkin AV, Benco A, Mlyncek M, Kotwica J, Alwasel S and Harrath AH: Transcription factor $\mathrm{p} 53$ regulates healthy human ovarian cells function. C R Biol 342: 186-191, 2019.

35. Elmissiry MM, Ali AG, Abulfotooh A, Moussa AA and Ali GA Factors determining the amount of residual urine in men with bladder outlet obstruction: Could it be a predictor for bladder contractility? Arab J Urol 12: 214-218, 2014.

36. Bosch R, Abrams P, Averbeck MA, Finazzi Agró E, Gammie A, Marcelissen T and Solomon E: Do functional changes occur in the bladder due to bladder outlet obstruction? - ICI-RS 2018. Neurourol Urodyn 38 (Suppl 5): S56-S65, 2019.

37. Yang R, Amir J, Liu H and Chaqour B: Mechanical strain activates a program of genes functionally involved in paracrine signaling of angiogenesis. Physiol Genomics 36: 1-14, 2008

38. Guo Q, Wu Y, Hou Y, Liu Y, Liu T, Zhang H, Fan C, Guan H, Li Y, Shan Z, et al: Cytokine Secretion and Pyroptosis of Thyroid Follicular Cells Mediated by Enhanced NLRP3, NLRP1, NLRC4, and AIM2 Inflammasomes Are Associated With Autoimmune Thyroiditis. Front Immunol 9: 1197, 2018

39. Bullon P, Pavillard LE and de la Torre-Torres R: Inflammasome and Oral Diseases. Exp Suppl 108 (Suppl 108): 153-176, 2018

40. Rom M, Waldert M, Klingler HC and Klatte T: Bladder outlet obstruction in men with acute urinary retention: An urodynamic study. World J Urol 31: 1045-1050, 2013.

41. Imamura M, Kanematsu A, Yamamoto S, Kimura Y, Kanatani I, Ito N, Tabata Y and Ogawa O: Basic fibroblast growth factor modulates proliferation and collagen expression in urinary bladder smooth muscle cells. Am J Physiol Renal Physiol 293 F1007-F1017, 2007.

42. Averbeck MA, De Lima NG, Motta GA, Beltrao LF, Abboud Filho NJ, Rigotti CP, Dos Santos WN, Dos Santos SKJ, Da Silva LFB and Rhoden EL: Collagen content in the bladder of men with LUTS undergoing open prostatectomy: A pilot study. Neurourol Urodyn 37: 1088-1094, 2018. 
43. Yang L, Liu R, Wang X and He D: Imbalance between matrix metalloproteinase-1 (MMP-1) and tissue inhibitor of metalloproteinase-1 (TIMP-1) contributes to bladder compliance changes in rabbits with partial bladder outlet obstruction (PBOO). BJU Int 112: E391-E397, 2013.

44. Bellucci CHS, Ribeiro WO, Hemerly TS, de Bessa J Jr, Antunes AA, Leite KRM, Bruschini H, Srougi M and Gomes CM: Increased detrusor collagen is associated with detrusor overactivity and decreased bladder compliance in men with benign prostatic obstruction. Prostate Int 5: 70-74, 2017.

45. Backhaus BO, Kaefer M, Haberstroh KM, Hile K, Nagatomi J, Rink RC, Cain MP, Casale A and Bizios R: Alterations in the molecular determinants of bladder compliance at hydrostatic pressures less than $40 \mathrm{~cm}$. H2O. J Urol 168: 2600-2604, 2002.

46. Chen S, Peng C, Wei X, Luo D, Lin Y, Yang T, Jin X, Gong L, Li $\mathrm{H}$ and Wang K: Simulated physiological stretch increases expression of extracellular matrix proteins in human bladder smooth muscle cells via integrin $\alpha 4 / \alpha v-F A K-E R K 1 / 2$ signaling pathway. World J Urol 35: 1247-1254, 2017.
47. Gosling JA, Kung LS, Dixon JS, Horan P, Whitbeck C and Levin RM: Correlation between the structure and function of the rabbit urinary bladder following partial outlet obstruction. J Urol 163: 1349-1356, 2000.

48. Herz DB, Aitken K and Bagli DJ: Collagen directly stimulates bladder smooth muscle cell growth in vitro: Regulation by extracellular regulated mitogen activated protein kinase. J Urol 170: 2072-2076, 2003.

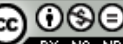

This work is licensed under a Creative Commons Attribution-NonCommercial-NoDerivatives 4.0 International (CC BY-NC-ND 4.0) License. 